\title{
Ön Çapraz Bağ ve Medial Menisküs Yırtığının Diz Ekstansiyon ve Fleksiyon İzokinetik Pik Tork Kuvvetine Etkisi ve Cybex Test Protokolü Uygulaması: Vaka Takdimi* $^{*}$
}

\author{
The Effect Of Anterior Cruciate Ligament And Medial Meniscus Rupture On \\ Knee Extension And Flexion Isokinetic Peak Torque Strength And Cybex Test \\ Protocol: Case Report
}

\author{
ORİJINAL ARAŞTIRMA/ \\ ORIGINAL RESEARCH \\ Gökhan UMUTLU ${ }^{1 \dagger}$, \\ Ayhan Taner ERDOĞAN ${ }^{2}$, \\ Nasuh Evrim ACAR ${ }^{3}$
}

${ }^{1}$ Uluslararası Final Üniversitesi, Girne/KKTC.

https://orcid.org/0000-0002-4736-8772

2 Uluslararası Final Üniversitesi,

Girne/KKTC.

https://orcid.org/0000-0001-8941-213X

${ }^{3}$ Mersin Üniversitesi, Mersin.

https://orcid.org/0000-0003-0423-1642

\section{Yavın Bilgisi}

Gönderi Tarihi: 13.11.2018

Kabul Tarihi: 17.06.2019

Online Yayın Tarihi: 30.06.2019

\section{$\ddot{O} \mathbf{z}$}

Diz ekstansör ve fleksör kasların aktivite esnasında önemli dinamik stabilizörler olmalarının yanı sıra bu kas grubunda kuvvet değerlerinde meydana gelen bir azalma durumunda diz eklemi stabilitesi önemli derecede azalmaktadır. Bu bulgulardan hareketle, bu çalışmada basketbol müsabakasında dizin aşırı lateral rotasyon hareketi yönünde zorlanması sonucu sağ ve sol dizlerinden sakatlanan iki kadın sporcuda ön çapraz bağ (ACL) ve medial menisküs yırtığının diz ekstansiyon ve fleksiyon izokinetik pik tork kuvvet değerleri üzerindeki etkisi ve aynı zamanda ameliyattan 16 hafta sonra kişiye uygulanan düzenli Cybex test protokolünün kas kuvvet değerleri üzerindeki etkisini incelemek amaçlanmıştır. Çalışmada yer alan kadın sporcular diz ekleminin bilateral fleksiyon ve ekstansiyon ön test ölçüm değerlerine göre Cybex izokinetik dinamometre (ABD) kullanılarak 8 hafta ve 12 hafta olmak üzere haftada 3 gün farklı kasılma türlerini içeren bir ACL rehabilitasyon protokolüne tabi tutuldu. Cybex testleri sonucunda iki ay boyunca teste katılan kadın sporcunun sağ ve sol diz ekstansiyonfleksiyon pik tork kuvvet fark1 değerleri (Ekstansiyon Bazal: \% 26, 1. ay: \% 15, 2. ay: \%5; Fleksiyon Bazal: \% 11, 1. ay: \%19, 2. ay: \% 8); üç ay boyunca teste katılan kadın sporcunun sağ ve sol diz ekstansiyon-fleksiyon pik tork kuvvet farkı değerleri (Ekstansiyon Bazal: \% 40, 1. ay: \% 34, 2. ay: \% 24; 3. ay: \% 14; Fleksiyon Bazal: \% 19, 1. ay: $\% 9,2$. ay: $\%$ 5, 3. ay: \% 3); olarak bulunmuştur. ACL ameliyatlarından 16 hafta sonra uygulanmaya başlanan Cybex protokolünün sporcuların ekstremiteler arası kuvvet farklarını azaltarak spora dönüş sürecini hızlandırdığı ifade edilebilir.

Anahtar Kelimeler: Menisküs, Ön Çapraz Bağ, Pik Tork.

\begin{abstract}
Knee extensor and flexor muscles are functioning as essential dynamic stabilizers during activity and a possible strength loss in these muscle groups considerably resulted in knee joint stability. According to these findings, it was aimed to examine the effect of the anterior cruciate ligament rupture (ACL) and medial meniscus tear of two female basketball players who injured due to excessive lateral rotation of the knee movement during competition and whether a Cybex protocol could be useful to improve the muscle strength parameters applied to the participants 16 weeks after following an ACL reconstruction surgery. An ACL rehabilitation protocol that enables different contraction patterns was conducted using a Cybex dynamometer (USA), which is an isokinetic measuring device, 3 times/week throughout 8 and 12 weeks based on the examination results of the flexion and extension strengths of the knee joint of participants. Bilateral knee extension-flexion muscle strength deficit of the participant following two months of testing session (Extension Baseline: $26 \%$, 1st Month: 15\%, 2nd month: 5\%; Flexion Baseline: 11\%, 1st Month: $19 \%$, 2nd Month: $8 \%$ ); and following three months of rehabilitation session were found (Extension Baseline: $40 \%$, 1st Month:34\%, 2nd Month: $24 \%$, 3rd Month: 14\%; Flexion Baseline: 19\%, 1st Month 9\%, 2nd Month: 5\%, 3rd Month: 3\%), respectively. As a result, it can be stated that Cybex protocol, which was started 16 weeks after ACL operations, accelerated the return to sports by decreasing the strength differences between the extremities of athletes.
\end{abstract}

Keywords: Meniscus, Anterior Cruciate Ligament, Peak Torque. 
Umutlu, G., Erdoğan, A,T., ve Acar, N.,E.. (2019). Ön çapraz bağ ve medial menisküs yırtığının diz ekstansiyon ve fleksiyon izokinetik pik tork kuvvetine etkisi ve cybex test protokolü uygulaması: Vaka takdimi, CBÜ Beden Eğitimi ve Spor Bilimleri Dergisi, 14(1), 41-54.

\section{GİRIŞ}

Performans sporları göz önünde bulundurulduğunda basketbol, futbol ya da hentbol gibi temas sporları tibianın normal seviyelerin üzerinde internal ya da external rotasyona maruz kalması sonucunda sporcuların ön çapraz bă̆ (ACL) yaralanma prevelanslarının yüksek düzeyde olduğu spor branşlarındandır. Sprint, sıçrama ve ani yön değiştirme gerektiren bu mekanik unsurların tümü basketbol branşının karakteristiğine özgü performans unsurlarındandır (Emerson, 1993). Ancak ACL sakatlanmalarının nedenleri incelendiğinde herhangi bir fiziksel temas olmaksızın sporcularda görülen ACL yaralanmalarının oranı kadınlarda erkeklere göre 2-9 kat daha fazladır ve bu yaralanmaların görülme sıklığı yıldan yıla artış göstermektedir (Arendt, Agel ve Dick, 1999; Ireland, 2002).

Kadın sporcularda en sık görülen ACL yaralanma türü, temassız bir mekanizma sonucunda oluşan sakatlıklardır . Sporda temassız bir ACL hasarı, sporcunun ACL'yi başka bir sporcuyla doğrudan temas etmeden, kontrolsüz bir hareket sirasında meydana gelen sakatlanma türlerindendir. ACL yaralanmalarının ortalama \% 70-\% 78'i temassız bir mekanizma ile gerçekleşmektedir (Agel, Olson ve Dick, 2007; Boden, Griffin ve Garrett, 2000).

Yapılan araştırmalar ACL ameliyatı sonrası rehabilitasyon sürecinin en az 6-9 ay sürebildiğini, bu sürecin spora dönme sürecini geciktirebileceğini ve bazı durumlarda sporcunun sakatlık öncesi performans seviyesine ulaşabilmesini engellediğini belirtmişlerdir. Ayrıca, ACL operasyonu sonrası performansa dönüş süreci, kronik diz problemleri, diz instabilitesi, menisküs yırtıkları, kıkırdak yaralanmaları ve osteoartrit gelişimi gibi çeşitli sonuçlara bağlı olarak değişiklik göstermektedir (Lohmander, Ostenberg, Englund ve Roos, 2004).

Ergenlik öncesi döneme kadar cinsiyetler arasında ACL yaralanma oranlarında herhangi bir farklılık görülmemektedir. Yapılan literatür taramaları ACL yaralanmalarına neden olan faktörlerin sporcunun kondisyon durumu, beceri düzeyi, ACL boyutları, diz eklem laksite derecesi, Q açısı ve hormonel farklılıklara bağlı olarak değişiklik gösterdiğini belirtmişlerdir (Chappell, Yu, Kirkendall ve Garrett, 2002; Hewett, Myer ve Ford, 2005; Huston ve Wojtys, 1996). Bu çalışmaların sonuçları karşılaştırılmış ve bu faktörlerin bazıları, statik ve değiştirilemez olması sebebiyle müdahale için daha az elverişli olduğu ifade edilmiştir. $\mathrm{Bu}$ nedenle nöromüsküler özelliklere bağlı olarak ACL yaralanmaları meydana gelmeden önce bu performans öğelerine 
Umutlu, G., Erdoğan, A,T., ve Acar, N.,E.. (2019). Ön çapraz bağ ve medial menisküs yırtığının diz ekstansiyon ve fleksiyon izokinetik pik tork kuvvetine etkisi ve cybex test protokolü uygulaması: Vaka takdimi, $C B \ddot{U}$ Beden Ĕgitimi ve Spor Bilimleri Dergisi, 14(1), 41-54.

dikkat edilmesi ya da ACL stabilizasyon cerrahisi, ilk yaralanmayı takiben geciktirilmemeli ve rehabilitasyon sürecinin spora dönüş baş̧arısını etkilediği göz önünde bulundurulmalıdır. $\mathrm{Bu}$ çalışmada basketbol müsabakasında dizin aşırı lateral rotasyon hareketi yönünde zorlanması sonucu sağ ve sol dizlerinden sakatlanan ve MRG tetkiklerine göre medial menisküs yırtığı ve 1/3 proksimalde ve orta bölümde ön çapraz bağ konfigürasyonu ve sinyali, tibia da lateralde ekleme komşu yüzeye uzanan heterojen hiperintens kontüzyonel değişiklikler izlenen iki kadın sporcuda ACL ve medial menisküs yırtığının diz ekstansiyon ve fleksiyon izokinetik pik tork kuvvet değerleri üzerindeki etkisi ve aynı zamanda ameliyattan 16 hafta sonra kişiye uygulanan düzenli Cybex test protokolünün kas kuvvet değerleri üzerindeki etkisini incelemek amaçlanmıştır.

\section{YÖNTEM}

\section{Çalışma Grubu}

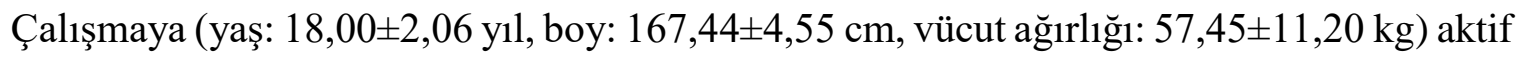
olarak profesyonel lig düzeyinde basketbol oynayan lisanslı iki kadın sporcu katılmıştır. Bireyler sağ ve sol dizlerinden sakatlanmış olup, MRG tetkiki sonuçlarına göre tibiada lateralde ekleme komşu yüzeye uzanan heterojen hiperintens kontüzyonel değişiklikler izlenmektedir. Medial menisküs posterior boynuzu korpusunda inferior ve superior artiküler yüzeye doğru uzanımı bulunan yırtık izlenmektedir. 1/3 proksimalde ve orta bölümde ön çapraz bağ konfigürasyonu ve sinyali net olarak şekillendirilememiş olup bu düzeyde heterojen sinyaller izlenmektedir. Total/totale yakın yırtık açısından klinik ve fizik muayene ile birlikte değerlendirilmesi önerilmiş ve 1/3 inferior'da ACL konfigürasyonu ve sinyalleri normal düzeyde bulunmuştur. Eklem içinde ve suprapatellar bursada mayi izlenmektedir. Ayrica medial ve lateral kollateral ligamanlar çevresinde mayii izlenmiş ve sinyallerin yer yer arttı̆̆ı görüşmüş̧ür. 

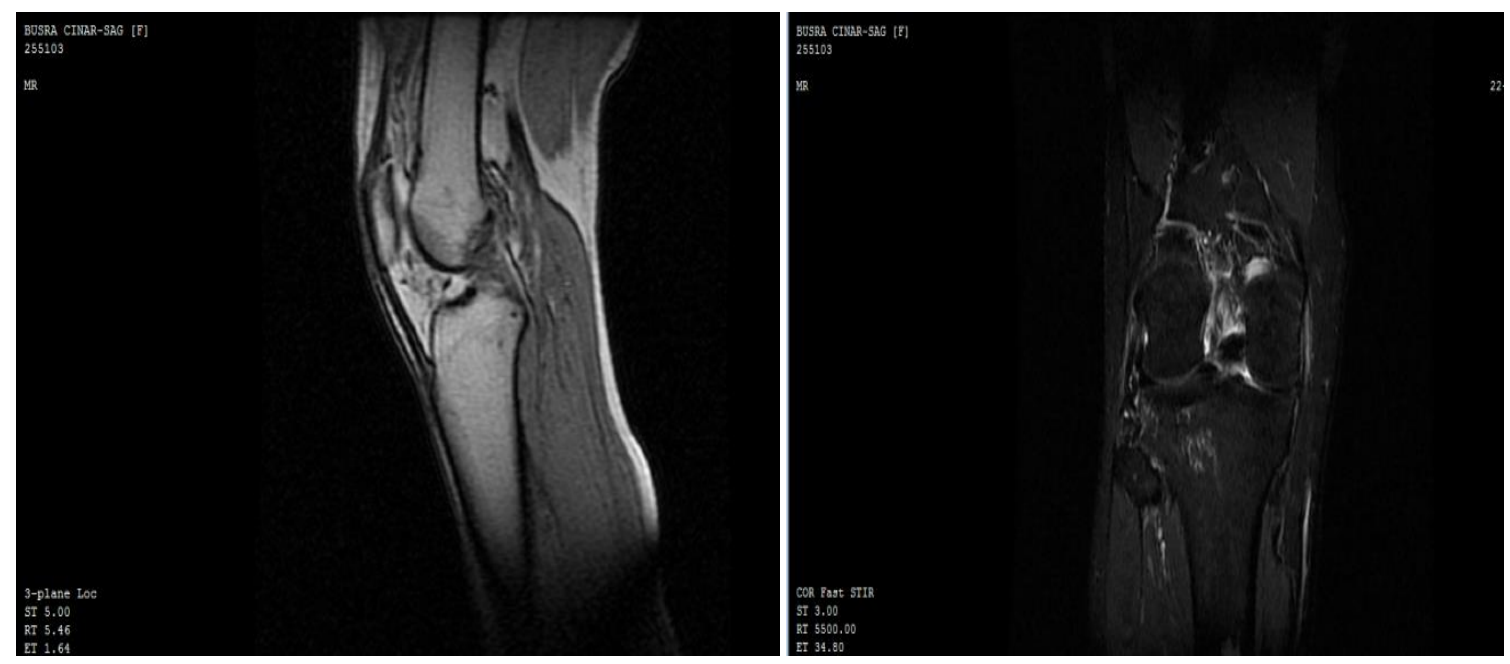

Resim 1: Çalışmaya katılan sporcuların $M R G$ görüntüleri

\section{Veri Toplama Aracı}

Sporculara ameliyattan 16 hafta sonra Cybex protokolünün uygulanmaya başlamasından önce diz ekstansiyon ve fleksiyon izokinetik kuvvet testleri yapılmıştır. Katılımcılar uyluk, gövde ve pelvis bölgelerinden koltuğa bantlar aracılığı ile bağlanmış ayrıca, ayak bileği eklemi yastıklı bir ped ile dinomometre koluna sabitlenmiştir. Kuvvet kolu ve birey pozisyonu, rotasyon femoral epikondilin laterali hizasında olacak şekilde ayarlanmıştır. Fleksiyon ve ekstansiyon açıları bacak tam ekstansiyon pozisyonunda $0^{\circ}$ ve fleksiyonda $90^{\circ}$ olarak ayarlanmış ve yerçekimi düzeltmesi yapılmıştır. Sporculara test öncesi gerekli açıklamalar yapılmış ve test hakkında bilgi verilmiştir.

Bireyin teste alışması için konsantrik 1 set 8 tekrar diz ekstansiyonu ve fleksiyonu yapmış, ardından 3 set 5 tekrar diz ekstansiyonu ve fleksiyonunu 60\% sn açısal hızda testi gerçekleştirmiştir. Testler sırasında bireye sözel uyaranlar verilmiştir. Katılımcılar bilateral kuvvet değerleri farkları belirlendikten 1 hafta sonra fark yüzdeleri göz önünde bulundurulmuş olup bir sporcuya 2 ay boyunca haftada 3 gün 2 set, bilateral kuvvet kaybı yüksek olan sporcuya 3 ay boyunca haftada 3 gün ve 2 set olmak üzere birer gün arayla Tablo 1'de belirtilen ACL rehabilitasyon protokolü kullanılarak düzenli olarak Cybex testlerine katılmışlardır. 
Umutlu, G., Erdoğan, A,T., ve Acar, N.,E.. (2019). Ön çapraz bağ ve medial menisküs yırtığının diz ekstansiyon ve fleksiyon izokinetik pik tork kuvvetine etkisi ve cybex test protokolü uygulaması: Vaka takdimi, $C B \ddot{U}$ Beden Ĕgitimi ve Spor Bilimleri Dergisi, 14(1), 41-54.

Tablo 1: Sporculara uygulanan Cybex test protokolü

\begin{tabular}{ccccc}
\hline Test türü & Açısal hız & Dinlenme ve Tekrar & \multicolumn{2}{c}{ Kasılma Türleri } \\
\hline CPM & $90 \%$ sn & 30 saniye x 10 tekrar & \multicolumn{2}{c}{ Con/Con } \\
İzokinetik & $60 \%$ sn & 30 saniye x 10 tekrar & Con/Con & Ecc/Con \\
İzometrik & $45^{\circ}-5 \mathrm{sn}$ & 30 saniye x 10 tekrar & Con/Con & Ecc/Con \\
İzotonik & $30-3-N e w t o n$ metre & 30 saniye x 10 tekrar & Con/Con & Ecc/Con \\
CPM & $90 \%$ Con & 30 saniye x 10 tekrar & \multicolumn{2}{c}{ Con } \\
\hline
\end{tabular}

\section{Verilerin Analizi}

Katılımcıların test protokolüne dahil olduğu sürelere göre Bazal, 1. ay, 2. ay ve Bazal, 1. ay, 2. ay ve 3. ay olmak üzere bilateral ekstansiyon pik tork, bilateral fleksiyon pik tork ve H:Q oranları tanımlayıcı istatistik analizleri kullanılarak rapor edilmiştir.

\section{BULGULAR}

Araştırmaya katılan ve iki ay boyunca ACL rehabilitasyon protokolü uygulanan sporcunun ön test kontrol değerleri göz önünde bulundurulduğunda ekstansiyon sağ (176 Nm) ve ekstansiyon sol $(237 \mathrm{Nm})$ değerleri arasında \%26 bir kuvvet kaybı bulunurken fleksiyon sağ (89 Nm) ve fleksiyon sol $(100 \mathrm{Nm})$ değerleri arasında \%11 bir kuvvet kaybı gözlemlenmiştir. Bilateral H:Q oranları göz önünde bulundurulduğunda H:Q sağ (0.51) ve H:Q sol (0.42) olarak tespit edilmiştir.

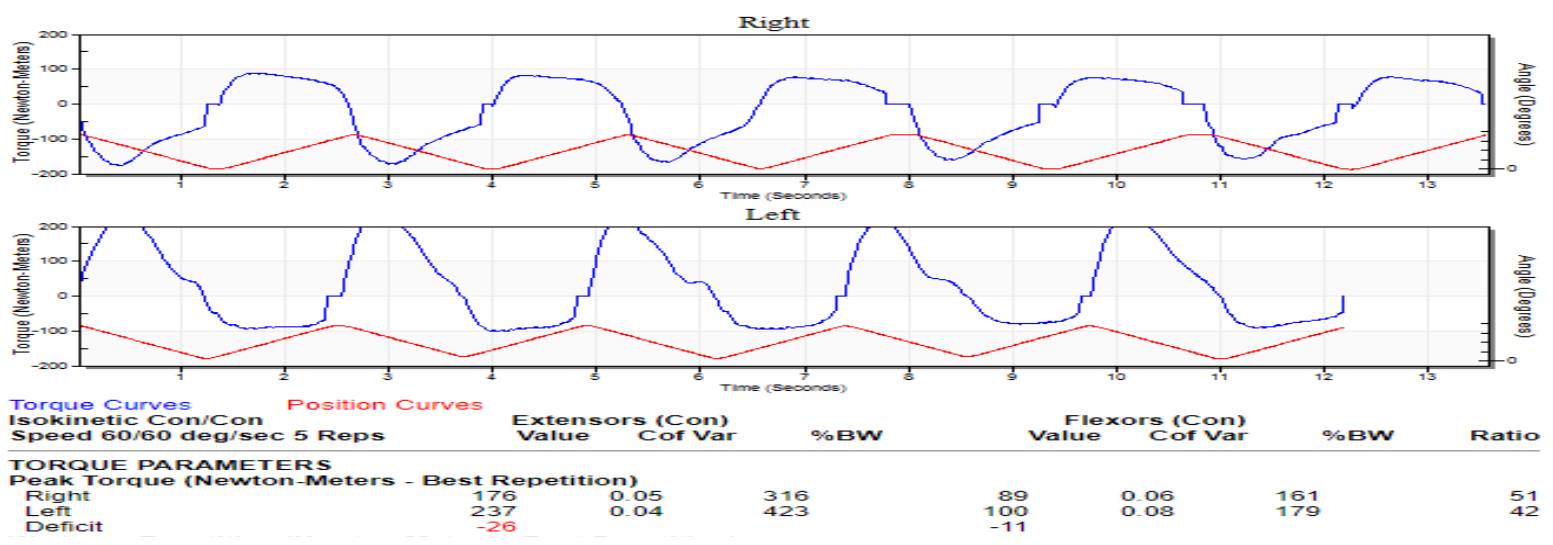

Grafik 1. İki ay boyunca Cybex testlerine katılan sporcunun ön test sağ ve sol diz ekstansiyon-fleksiyon kuvvet değerleri 
Umutlu, G., Erdoğan, A,T., ve Acar, N.,E.. (2019). Ön çapraz bağ ve medial menisküs yırtığının diz ekstansiyon ve fleksiyon izokinetik pik tork kuvvetine etkisi ve cybex test protokolü uygulaması: Vaka takdimi, $C B \ddot{U}$ Beden Ĕgitimi ve Spor Bilimleri Dergisi, 14(1), 41-54.

Sporcunun 1. ay sonunda değerleri kontrol edildiğinde ekstansiyon sağ (202 Nm) ve ekstansiyon sol (237 Nm) değerleri arasında \%15 bir kuvvet kaybı bulunurken fleksiyon sağ (98 $\mathrm{Nm})$ ve fleksiyon sol $(121 \mathrm{Nm})$ değerleri arasında \%19 bir kuvvet farkı gözlemlenmiştir. Ayrıca bilateral H:Q oranları göz önünde bulundurulduğunda H:Q sağ (0.49) ve H:Q sol (0.51) olarak tespit edilmiştir.

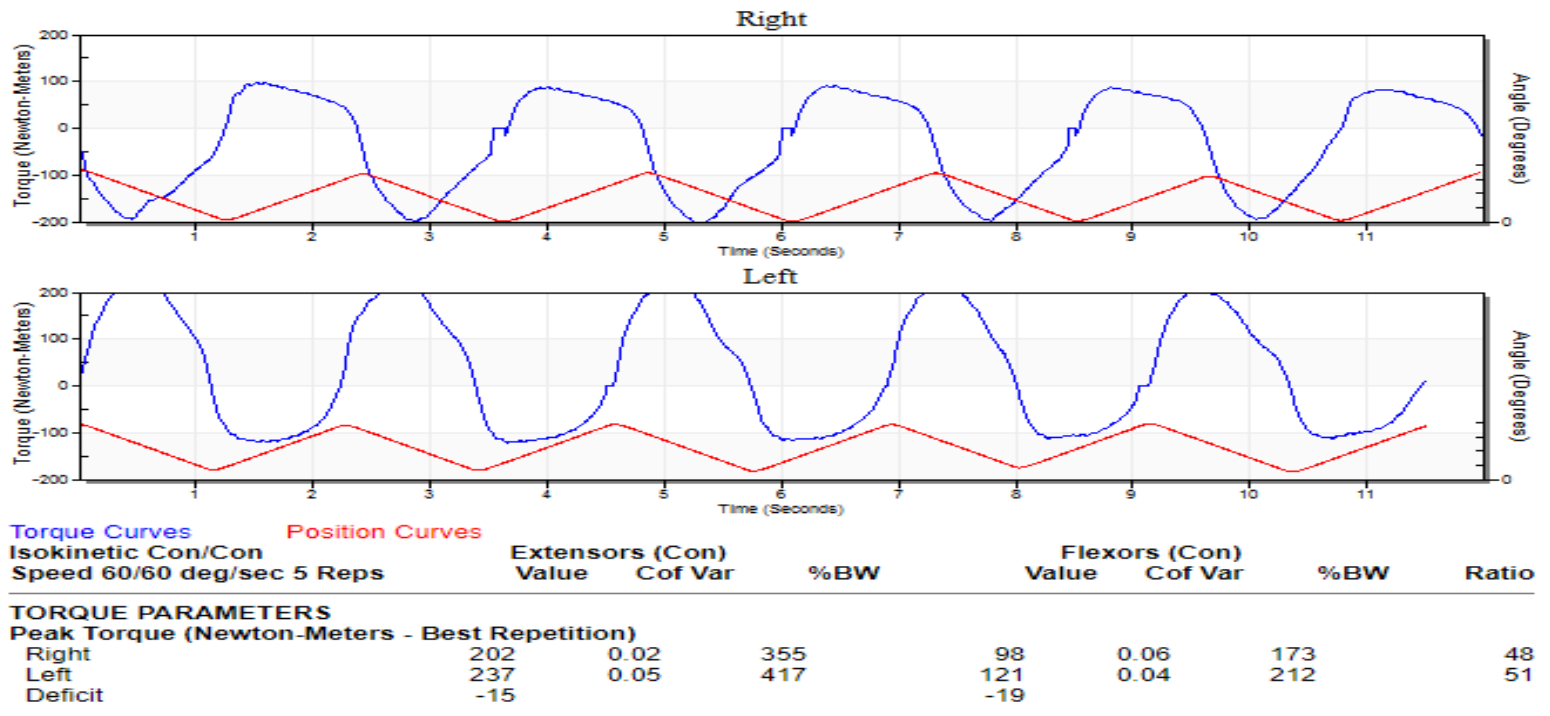

Grafik 2. İki ay boyunca Cybex testlerine katılan sporcunun 1. ay sonunda sağ ve sol diz ekstansiyon-fleksiyon kuvvet değerleri

Sporcunun 2. ay sonunda değerleri kontrol edildiğinde opere olan sağ diz ekstansiyon sağ (255 Nm) ve ekstansiyon sol $(243 \mathrm{Nm})$ değerleri arasında \%5 bir kuvvet kaybı bulunurken fleksiyon sağ $(106 \mathrm{Nm})$ ve fleksiyon sol $(98 \mathrm{Nm})$ değerleri arasında opere olan diz eklemi lehine \%8 bir kuvvet farkı gözlemlenmiştir. Ayrıca bilateral H:Q oranları göz önünde bulundurulduğunda H:Q sağ (0.42) ve H:Q sol (0.40) olarak tespit edilmiştir. 
Umutlu, G., Erdoğan, A,T., ve Acar, N.,E.. (2019). Ön çapraz bağ ve medial menisküs yırtığının diz ekstansiyon ve fleksiyon izokinetik pik tork kuvvetine etkisi ve cybex test protokolü uygulaması: Vaka takdimi, CBÜ Beden Ĕgitimi ve Spor Bilimleri Dergisi, 14(1), 41-54.
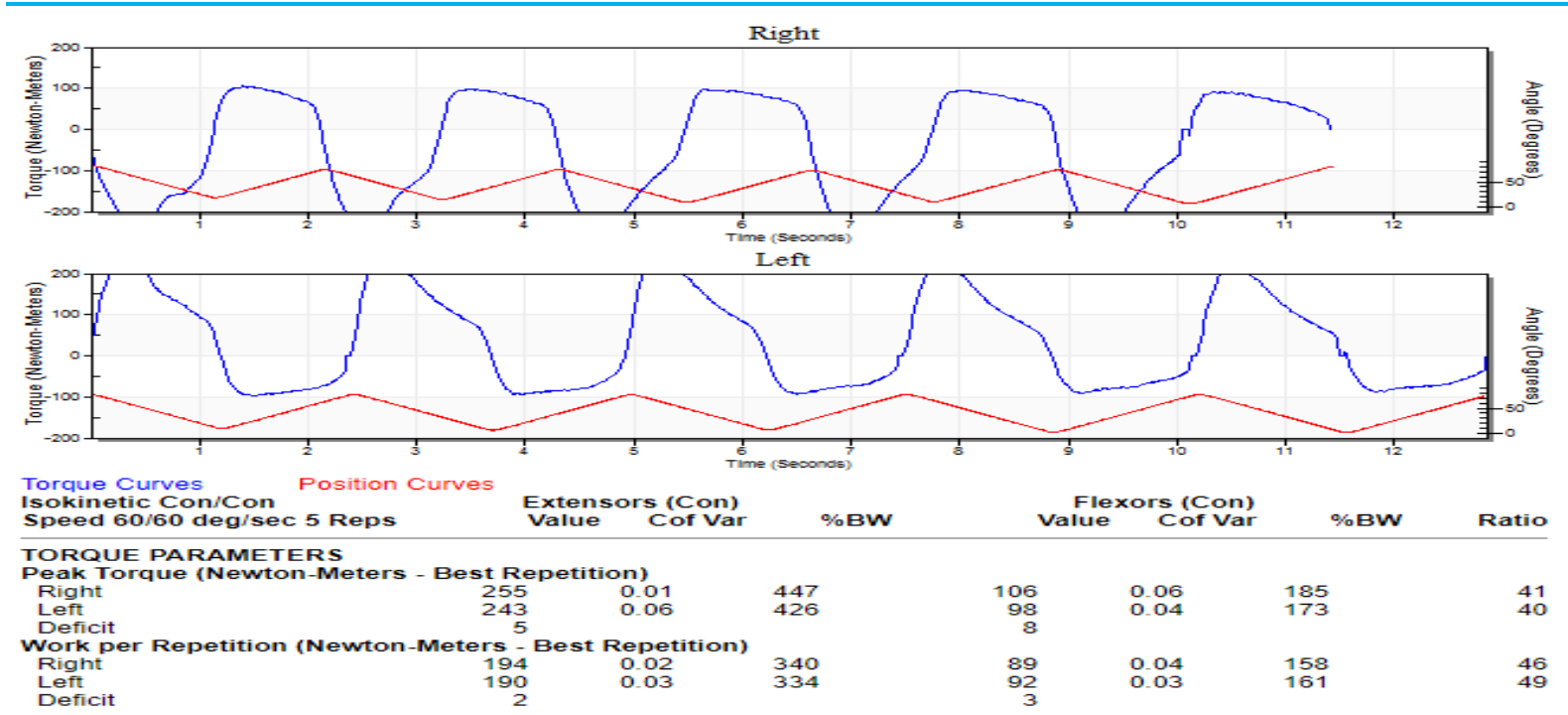

Grafik 3. İki ay boyunca Cybex testlerine katılan sporcunun 2. ay sonunda sağ ve sol diz ekstansiyon-fleksiyon kuvvet değerleri

Tablo 2: İki ay boyunca Cybex testlerine katılan sporcunun izokinetik pik tork parametreleri

\begin{tabular}{lcccccccc}
\hline Test & $\begin{array}{c}\text { Extansiyon } \\
\text { Sağ } \\
(\mathbf{N m})\end{array}$ & $\begin{array}{c}\text { Ekstansiyon } \\
\text { Sol } \\
(\mathbf{N m})\end{array}$ & $\begin{array}{c}\text { H:Q } \\
\text { Oranı } \\
(\mathbf{S a g})\end{array}$ & $\begin{array}{c}\text { Deficit } \\
(\boldsymbol{\%})\end{array}$ & $\begin{array}{c}\text { Fleksiyon } \\
\text { Sağ } \\
(\mathbf{N m})\end{array}$ & $\begin{array}{c}\text { Fleksiyon } \\
\text { Sol } \\
(\mathbf{N m})\end{array}$ & $\begin{array}{c}\text { H:Q } \\
\text { Oranı } \\
(\text { Sol) }\end{array}$ & $\begin{array}{c}\text { Deficit } \\
(\%)\end{array}$ \\
\hline Bazal & 176 & 237 & 0,51 & -26 & 89 & 100 & 0,42 & -11 \\
1. ay & 202 & 237 & 0,49 & -15 & 98 & 121 & 0,51 & -19 \\
2. ay & 255 & 243 & 0,42 & 5 & 106 & 98 & 0,40 & 8 \\
\hline
\end{tabular}

Araştırmaya katılan ve üç ay boyunca ACL rehabilitasyon protokolü uygulanan kadın sporcunun ön test kontrol değerleri göz önünde bulundurulduğunda ise ekstansiyon sağ (171 Nm) ve ekstansiyon sol $(102 \mathrm{Nm})$ değerleri arasında \%40 bir kuvvet kaybı bulunurken fleksiyon sağ (80 Nm) ve fleksiyon sol $(65 \mathrm{Nm})$ değerleri arasında \%19 bir kuvvet kaybı gözlemlenmiştir. Ayrıca bilateral H:Q oranları göz önünde bulundurulduğunda H:Q sağ (0.47) ve H:Q sol (0.64) olarak tespit edilmiştir. 
Umutlu, G., Erdoğan, A,T., ve Acar, N.,E.. (2019). Ön çapraz bağ ve medial menisküs yırtığının diz ekstansiyon ve fleksiyon izokinetik pik tork kuvvetine etkisi ve cybex test protokolü uygulaması: Vaka takdimi, CBÜ Beden Ĕgitimi ve Spor Bilimleri Dergisi, 14(1), 41-54.

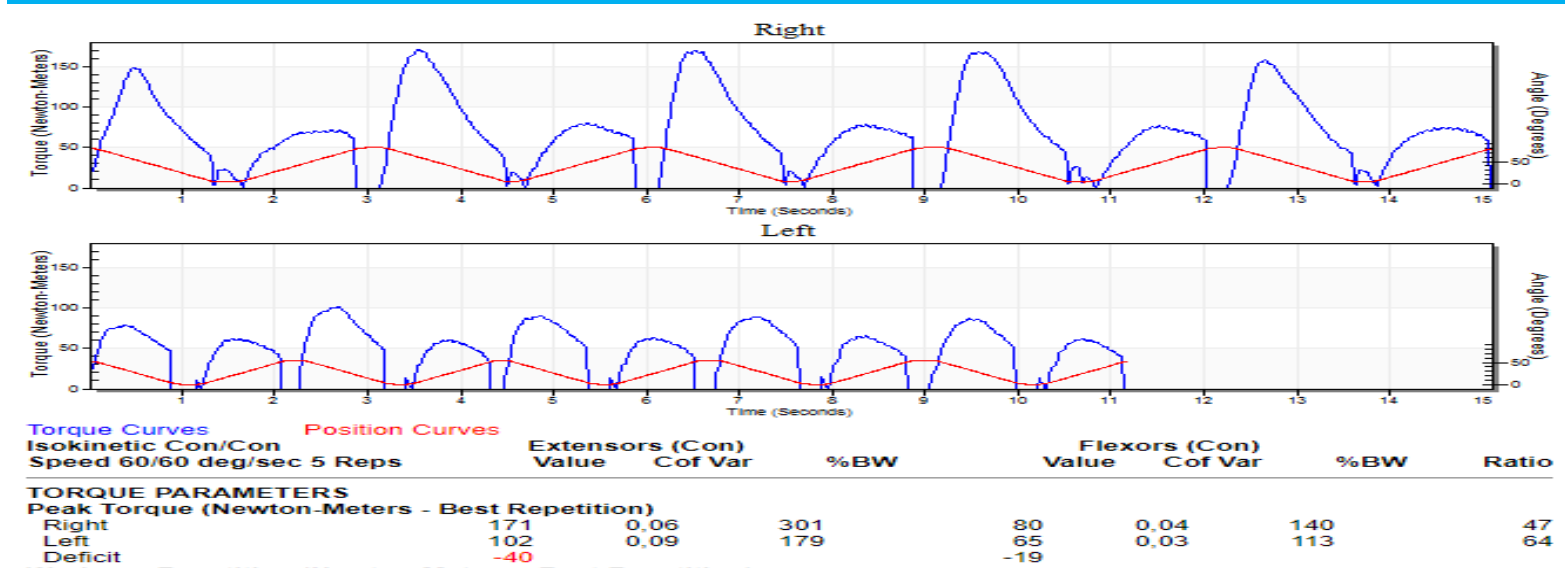

Grafik 4. Üç ay boyunca Cybex testlerine katılan sporcunun ön test sağ ve sol diz ekstansiyon-fleksiyon kuvvet değerleri

Sporcunun 1. ay sonunda değerleri kontrol edildiğinde ekstansiyon sağ (186 Nm) ve ekstansiyon sol (122 Nm) değerleri arasında \%34 bir kuvvet kaybı bulunurken fleksiyon sağ (92 $\mathrm{Nm})$ ve fleksiyon sol $(84 \mathrm{Nm})$ değerleri arasında \%9 bir kuvvet farkı gözlemlenmiştir. Ayrıca bilateral H:Q oranları göz önünde bulundurulduğunda H:Q sağ (0.49) ve H:Q sol (0.69) olarak tespit edilmiştir.
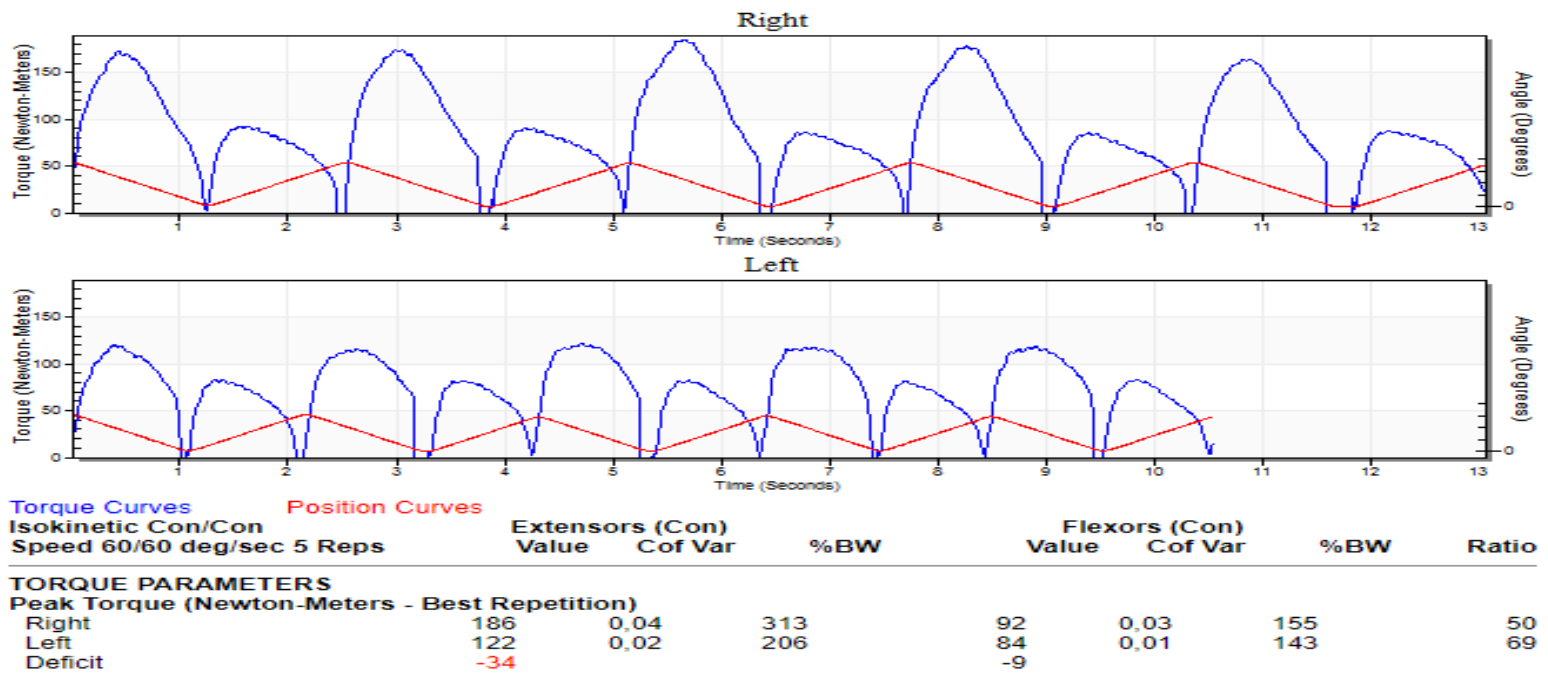

Grafik 5. Üç ay boyunca Cybex testlerine katılan sporcunun 1. ay sağ ve sol diz ekstansiyon-fleksiyon kuvvet değerleri

Sporcunun 2. ay sonunda değerleri kontrol edildiğinde diz ekstansiyon sağ (195 Nm) ve ekstansiyon sol (149 Nm) değerleri arasında \%24 bir kuvvet kaybı bulunurken fleksiyon sağ (91 $\mathrm{Nm})$ ve fleksiyon sol $(85 \mathrm{Nm})$ değerleri arasında \%5 bir kuvvet farkı gözlemlenmiştir. Ayrıca 
Umutlu, G., Erdoğan, A,T., ve Acar, N.,E.. (2019). Ön çapraz bağ ve medial menisküs yırtığının diz ekstansiyon ve fleksiyon izokinetik pik tork kuvvetine etkisi ve cybex test protokolü uygulaması: Vaka takdimi, CBÜ Beden Ĕgitimi ve Spor Bilimleri Dergisi, 14(1), 41-54.

bilateral H:Q oranları göz önünde bulundurulduğunda H:Q sağ (0.47) ve H:Q sol (0.57) olarak tespit edilmiştir.
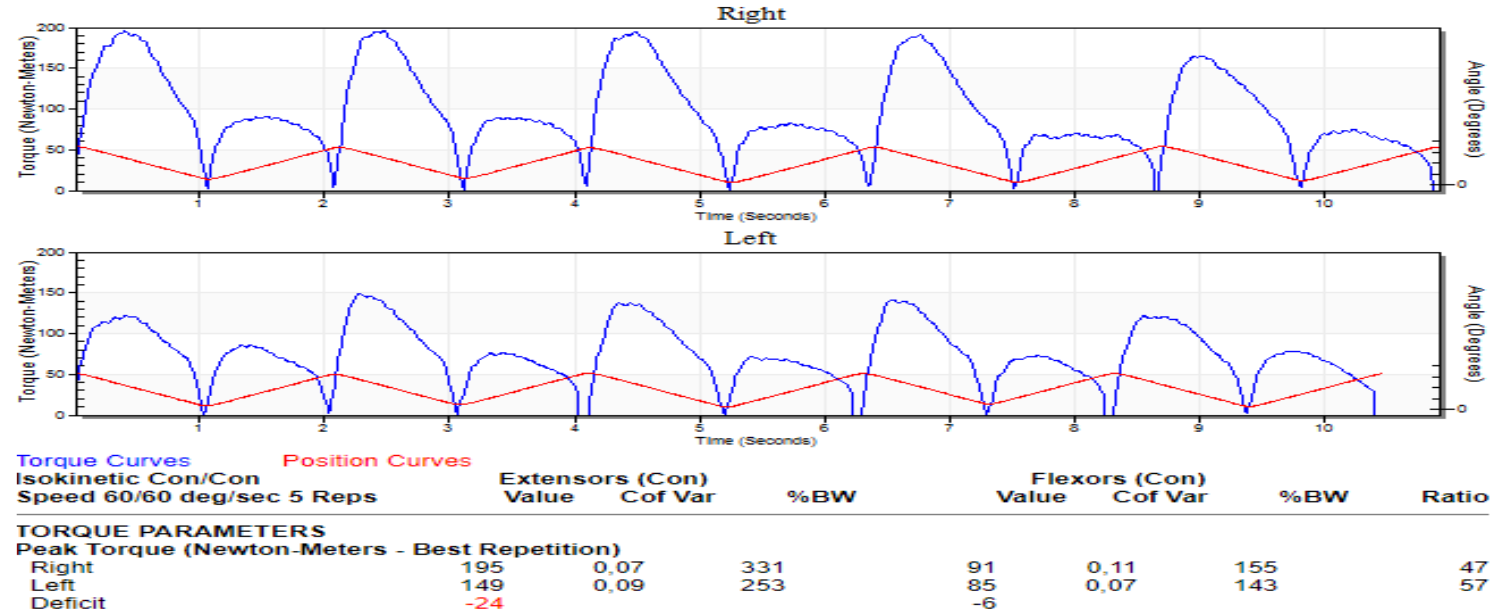

Grafik 6. Üç ay boyunca Cybex testlerine katılan sporcunun 2. ay sağ ve sol diz ekstansiyon-fleksiyon kuvvet değerleri

Sporcunun 3. ay sonunda değerleri kontrol edildiğinde ise diz ekstansiyon sağ (202 Nm) ve ekstansiyon sol $(174 \mathrm{Nm})$ değerleri arasında \%14 bir kuvvet kaybı bulunurken fleksiyon sağ $(80 \mathrm{Nm})$ ve fleksiyon sol $(77 \mathrm{Nm})$ değerleri arasında \%3 bir kuvvet farkı gözlemlenmiştir. Ayrıca bilateral H:Q oranları göz önünde bulundurulduğunda H:Q sağ (0.40) ve H:Q sol (0.44) olarak bulunmuştur (Tablo 3).
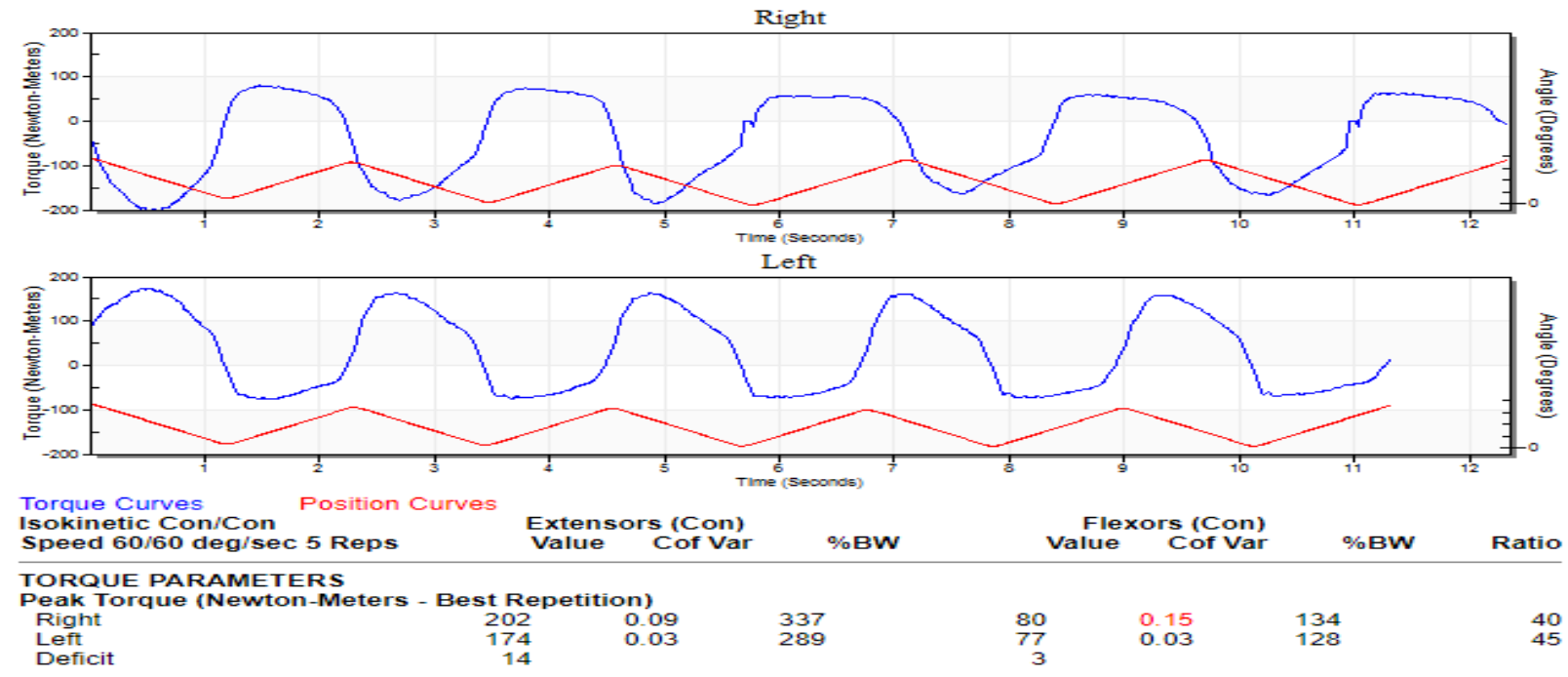

Grafik 7. Üç ay boyunca Cybex testlerine katılan sporcunun 2. ay sağ ve sol diz ekstansiyon-fleksiyon kuvvet değerleri 
Umutlu, G., Erdoğan, A,T., ve Acar, N.,E.. (2019). Ön çapraz bağ ve medial menisküs yırtı̆̆ının diz ekstansiyon ve fleksiyon izokinetik pik tork kuvvetine etkisi ve cybex test protokolü uygulaması: Vaka takdimi, CBÜ Beden Eğitimi ve Spor Bilimleri Dergisi, 14(1), 41-54.

Tablo 3: Üç ay boyunca Cybex testlerine katılan sporcunun izokinetik pik tork parametreleri

\begin{tabular}{lcccccccc}
\hline Test & $\begin{array}{c}\text { Extansiyon } \\
\text { Sağ } \\
(\mathbf{N m})\end{array}$ & $\begin{array}{c}\text { Ekstansiyon } \\
\text { Sol } \\
(\mathbf{N m})\end{array}$ & $\begin{array}{c}\text { H:Q } \\
\text { Oranı } \\
(\mathbf{S a g})\end{array}$ & $\begin{array}{c}\text { Deficit } \\
(\boldsymbol{\%})\end{array}$ & $\begin{array}{c}\text { Fleksiyon } \\
\mathbf{S a g} \\
(\mathbf{N m})\end{array}$ & $\begin{array}{c}\text { Fleksiyon } \\
\text { Sol } \\
(\mathbf{N m})\end{array}$ & $\begin{array}{c}\text { H:Q } \\
\text { Oranı } \\
(\mathbf{S o l})\end{array}$ & $\begin{array}{c}\text { Deficit } \\
(\%)\end{array}$ \\
\hline Bazal & 171 & 102 & 0,47 & -40 & 80 & 65 & 0,64 & -19 \\
$\mathbf{1 . ~ a y}$ & 186 & 122 & 0,49 & -34 & 92 & 84 & 0,69 & -9 \\
2. ay & 195 & 149 & 0,47 & -24 & 91 & 85 & 0,57 & -5 \\
3. ay & 202 & 174 & 0,40 & 14 & 80 & 77 & 0,44 & 3 \\
\hline
\end{tabular}

\section{TARTIŞMA VE SONUÇ}

Kas kuvveti, başarılı spor performansındaki en önemli faktörlerden birisi olmasının yanı sıra sporcularda yaralanma rehabilitasyonunun etkinliğinin önemli bir göstergesidir. H:Q oranı, hamstrings ve quadriseps moment-moment paternleri arasındaki benzerlĭgi incelemek, ekstremitelerin fonksiyonel özelliklerini ve kas kuvveti dengesini değerlendirmek için kullanımı oldukça önemli olan ölçüm kriterlerindendir (Aagaard ve ark., 1995; Holmes ve Alderink, 1984; Li ve ark., 1996). Sporcuların performans düzeylerini izlemek ve sakatlanan oyuncuların rehabilitasyon sürecini takip edebilmek için çeşitli alt ekstremite gücü indeksleri mevcuttur. (Aagard ve ark., 1997; Lund-Hanssen ve ark., 1996). Araştırmacılar bu oranı hem cinsiyet hem de farklı yaş gruplarında ve rehabilitasyon ortamlarında incelemiş olup (Laird, 1981; Raunest, Sager ve Bürgener., 1996), bunlar arasında, hamstring/quadriceps pik tork oranı (H: Q oranı) en yaygın olarak değerlendirilen ölçüm parametrelerdendir. Agonist kasların antagonist diz kaslarına olan kuvvet oranı, hıza bağlı olarak meydana gelen hareketler sırasında diz ekleminin fonksiyonel özelliklerini, diz eklemi stabilitesini ve hamstring-quadriseps arasındaki kas aktivasyonunu ve dengesini incelemek için kullanılmıştır. H:Q oranı açısal hız ve pozisyona bağlı olarak değiş̧mekle birlikte (Aagard ve ark., 1998) sporcunun sakatlığa olan yatkınlığını yansıtabilmektedir (Bennell ve ark., 1998; Croce ve ark., 1996). Sağlıklı bireylerde H:Q oranları izokinetik testler sırasında 0.5 ila 0.8 arasındadır (Bennell ve ark., 1998).

Sporcuların rehabilitasyon programını takiben her ay sonunda $60^{\circ} /$ sn'lik açısal hızlarda yapılan izokinetik test performans kriterleri göz önünde bulundurulduğunda iki ay boyunca teste katılan kadın sporcunun sağ ve sol diz ekstansiyon-fleksiyon pik tork kuvvet fark1 değerleri (Ekstansiyon Bazal: \% 26, 1. ay: \% 15, 2. ay: \%5; Fleksiyon Bazal: \% 11, 1. ay: \%19, 2. ay: \% 8; H:Q Sağ; 0,51;0,49; 0,42 ve H:Q Sol: 0,42;0,51;0,40 ); üç ay boyunca teste katılan kadın 
Umutlu, G., Erdoğan, A,T., ve Acar, N.,E.. (2019). Ön çapraz bağ ve medial menisküs yırtığının diz ekstansiyon ve fleksiyon izokinetik pik tork kuvvetine etkisi ve cybex test protokolü uygulaması: Vaka takdimi, CBÜ Beden Eğitimi ve Spor Bilimleri Dergisi, 14(1), 41-54.

sporcunun sağ ve sol diz ekstansiyon-fleksiyon pik tork kuvvet farkı değerleri (Ekstansiyon Bazal: \% 40, 1. ay: \% 34, 2. ay: \% 24; 3. ay: \% 14; Fleksiyon Bazal: \% 19, 1. ay: \%9, 2. ay: \% 5, 3. ay: \% 3; H:Q Sağ; 0,47; 0,49; 0,47; 0,40 ve H:Q Sol: 0,64; 0,69; 0,57; 0,44) sporcuların rehabilitasyon testleri sonucunda bilateral alt ekstremite kuvvet ve H:Q farklarını minimize ederek sporcunun spor yaşamına dönmesinin nöromusküler unsurlar açısından uygun olduğunu göstermektedir. Bu çalışmada rehabilitasyon protokolü kullanılarak testlere tabi tutulan kadın basketbolcuların izokinetik ölçümler esnasında elde etmiş oldukları parametrelerin belirlenip sporcuya, antrenörlere ve kondisyonerlere rapor edilmesi sporcunun nöromusküler etmenlere bağlı olarak tekrardan sakatlanma riskinin azaltılabilmesi için önemlilik arz etmektedir. Özellikle, kadın basketbolcularda ACL yaralanma prevelansının yüksek düzeyde olması ve sporcuların ACL rekonstrüktif cerrahisinden sonra uygun olmayan koşullarda antrene edilerek optimal rehabilitasyon sürecinden daha kısa bir süre içerisinde spor hayatına dönmeye zorlanıyor olması sebebiyle her iki kadın sporcunun da H:Q oranları ve bilateral ektremite kuvvet farkı yüzdeleri göz önünde bulundurularak sporcuların operasyondan sonra 9-12 ay gibi optimal bir sürede sahaya dönüşleri sağlanmış olup çalışmaya katılan her iki sporcu da profesyonel spor hayatına dönüş yapabilmiştir.

ACL yaralanması riskinde erkek ve kadın sporcularda farklı oranlarda yaralanma sıklığının görülmesinin altında yatan mekanizma çok faktörlü olabilir. Ön çapraz bağ yaralanması oranlarında cinsiyet farklılığının altında yatan mekanizmaları açıklamak için anatomik, hormonel, nöromüsküler ve biyomekanik farklılıklar üzerine çeşitli teoriler önerilmiştir (Hewett ve ark., 2006). Dolayısıyla ACL yaralanması mekanizması ile ilişkili hem dışsal hem de içsel risk faktörlerinin tanımlanması, yüksek riskli bireylere hedeflenmiş profilaktik tedavi yöntemleri için oldukça önemli olabilir. Kadın ve erkek sporcuların ACL yaralanma prevelansı ülkemizde de yıldan yıla artış göstermektedir. Sporcuların yaralanmalarına sebep olan bu unsurlar genelde nöromüsküler faktörlere bağlı olarak meydana geldiği düşünülse de özellikle kadın basketbolcularda görülme sıklığı yüksek düzeyde olan ACL yaralanmalarının ardında yatan bir çok mekanizma mevcuttur. Yapılan literatür çalışması sonucunda ACL hasarı için daha fazla risk altında olan sporcuları tanımlamak ve bu nedenle daha fazla sporcunun ACL yaralanmalarına maruz kalmadan önce bir dizi tarama testleri kullanılarak diz valgus açıları yüksek ve instabil sıçrama/iniş mekaniği olan bireyleri tanımlayarak ACL yaralanmalarına sebep olabilecek risk 
Umutlu, G., Erdoğan, A,T., ve Acar, N.,E.. (2019). Ön çapraz bağ ve medial menisküs yırtığının diz ekstansiyon ve fleksiyon izokinetik pik tork kuvvetine etkisi ve cybex test protokolü uygulaması: Vaka takdimi, CBÜ Beden Eğitimi ve Spor Bilimleri Dergisi, 14(1), 41-54.

faktörlerinin belirlenmesinin oldukça önemli olduğu ifade edilmiştir (Barber-Westin, Smith, Campbell \& Noyes 2010). Ayrıca, kadın basketbolculara ve voleybol oyuncularına yönelik olarak tasarlanan nöromüsküler programların uygulanması sonucunda, zayıf biyomekaniği düzeltmede ve yatay ve dikey sıçrama testi ile tanımlanan iniş modellerini iyileştirmede başarılı olduğu belirtilmiştir (Noyes ve ark., 2012). Bu çalışmada yer alan kadın sporcuların hem Kadınlar Basketbol Süper Ligi'nde hem de Türkiye Kadınlar Basketbol Ligi düzeyinde performans sergiliyor olmaları ve yoğun bir antrenman ve maç periyoduna tabi tutuluyor olmaları sebebiyle sporcuların yeterli düzeyde dinlenme firsatlarının olmadığı ve dolayısıyla organizma üzerinde oluşan yorgunluk, stres vb. unsurlara bağlı olarak sporcuların müsabaka esnasında temas olmayan pozisyonlarda ACL yaralanmalarına maruz kaldıkları ileri sürülebilir.

Profesyonel düzeyde performans sergileyen kadın sporcuların herhangi bir temasa maruz kalmadan ACL yaralanmalarına maruz kalma oranı erkek sporcularla karşılaştırıldığında kadın sporcuların 3,5 kat daha fazla risk taşıdıkları ve bu oranın genelde maladaptif nöromüsküler aktivasyon modellerinden ve instabil sıçrama/iniş biyomekaniğinden kaynaklandığı belirtilmiştir (Voskanian, 2013). Araştırma bulgularına göre, ideal ACL önleme programının, vücut mekaniği ve iniş tekniği ile ilgili temel eğitimin ve geribildirimin yanı sıra, pliometrik, nöromusküler uyum ve kas gruplarının kuvvet düzeylerini arttırmayı kapsayan egzersizler ve uygulamalar da içermesi gerektiği ileri sürülmüştür.

Sonuç olarak; uygulanan Cybex protokolünün izokinetik, izometrik, izotonik kontraksiyonları içeren bir yapıda olması, tüm rehabilitasyon süreci boyunca konsantrik ve egzantrik kas aktivasyonlarını bir arada uygulanılmasına olanak vermesi, sporcunun hangi açısal hızlarda ve hangi eklem hareket genişliğinde ne düzeyde kuvvet üretebildiğinin belirlenmesine olanak vermesi sebebiyle sporculara uygulanan Cybex protokolü sonucunda să̆ ve sol diz ekstansiyon ve fleksiyon kuvvetlerinin birbirine yaklaştı̆̆ı görülmekte olup aynı zamanda ameliyattan 16 hafta sonra uygulanmaya başlayan ön çapraz bağ (ACL) test prokolünün sporcularda operasyon sonrası bilateral kas kuvvet kaybının ve H:Q oranları arasındaki farkı minimize ederek sporcuların nöromusküler karakteristiklerini geliştirmede oldukça güvenilir ve etkili bir protokol olduğunu ve aynı zamanda bu protokollerin daha büyük örneklem popülasyonunda çalışılması gerektiği düşünülmektedir. 
Umutlu, G., Erdoğan, A,T., ve Acar, N.,E.. (2019). Ön çapraz bağ ve medial menisküs yırtığının diz ekstansiyon ve fleksiyon izokinetik pik tork kuvvetine etkisi ve cybex test protokolü uygulaması: Vaka takdimi, CBÜ Beden Eğitimi ve Spor Bilimleri Dergisi, 14(1), 41-54.

\section{KAYNAKLAR}

Aagaard, P., Simonsen, E.B., Beyer, N., Larsson, B., Magnusson, P. \& Kjaer, M. (1997). Isokinetic muscle strength and capacity for muscular knee joint stabilization in elite sailors. International Journal of Sports Medicine, 18(7),521-525.

Aagaard, P., Simonsen, E.B., Magnusson, S.P., Larsson, B. \& Dyhre-Poulsen, P. (1998). A new concept for isokinetic hamstring: quadriceps muscle strength ratio. The American Journal of Sports Medicine, 26(2),231-237.

Aagaard, P., Simonsen, E.B., Trolle, M., Bangsbo, J. \& Klausen, K. (1995). Isokinetic hamstring/quadriceps strength ratio: influence from joint angular velocity, gravity correction and contraction mode. Acta Physiologica Scandinavica, $154(4), 421-7$

Agel, J., Olson, D.E. \& Dick, R. (2007). Descriptive epidemiology of collegiate women's basketball injuries: National Collegiate Athletic Association Injury Surveillance System, 1988-1989 through 2003-2004. Journal of Athletic Training, 42,20210 .

Arendt, E.A., Agel, J. \& Dick, R. (1999). Anterior cruciate ligament injury patterns among collegiate men and women. Journal of Athletic Training, 34,86-92.

Barber-Westin, S.D., Smith, S.T., Campbell, T. \& Noyes, F.R. (2010). The drop-jump video screening test: retention of improvement in neuromuscular control in female volleyball players. The Journal of Strength \& Conditioning Research, 24(11),3055-62.

Bennell, K., Wajswelner, H., Lew, P., Schall-Riaucour, A., Leslie, S., Plant, D. \& Cirone, J. (1998). Isokinetic strength testing does not predict hamstring injury in Australian Rules footballers. British Journal of Sports Medicine, 32(4),309-14.

Boden, B.P., Griffin, L.Y. \& Garrett, W.E., Jr. (2000). Etiology and prevention of noncontact ACL injury. The Physician and Sportsmedicine, 8,53-60.

Chappell, J.D., Yu, B., Kirkendall, D.T. \& Garrett, W.E. (2002). A comparison of knee kinetics between male and female recreational athletes in stop-jump tasks. The American Journal of Sports Medicine, 30,261-267.

Croce, R.V., Pitetti, K.H., Horvat, M. \& Miller, J. (1996). Peak torque, average power, and hamstrings/quadriceps ratios in nondisabled adults and adults with mental retardation. Archives of Physical Medicine and Rehabilitation, 77(4),369-72.

Emerson, R.J. (1993). Basketball knee injuries and the anterior cruciate ligament. Clinics in Sports Medicine, 12(2),317-28.

Hewett, T.E., Myer, G.D. \& Ford, K.R. (2005). Biomechanical measures of neuromuscular control and valgus loading of the knee predict anterior cruciate ligament injury risk in female athletes: a prospective study. The American Journal of Sports Medicine, 33,492-501.

Hewett, T.E., Myer, G.D. \& Ford, K.R. (2006). Anterior cruciate ligament injuries in female athletes: Part 1, mechanisms and risk factors. The American Journal of Sports Medicine, 34(2),299-311.

Holmes, J.R. \& Alderink, G.J. (1984). Isokinetic strength characteristics of the quadriceps femoris and hamstring muscles in high school students. Physical Therapy, 64(6),914-8.

Huston, L.J. \& Wojtys, E.M. (1996). Neuromuscular performance characteristics in elite female athletes. The American Journal of Sports Medicine, 24,427-36. doi: 10.1177/036354659602400405.

Ireland, M.L. (2002). The female ACL: why is it more prone to injury? Orthopedic Clinics of North America, 33,637-51. doi: $10.1016 / \mathrm{S} 0030-5898(02) 00028-7$.

Laird, D.E. (1981). Comparison of quad to ham strength ratios of an intercollegiate soccer team. Athletic Training, 16,66-67.

Li, R.C., Maffulli, N., Hsu, Y.C. \& Chan, K.M. (1996). Isokinetic strength of the quadriceps and hamstrings and functional ability of anterior cruciate deficient knees in recreational athletes. British Journal of Sports Medicine, 30(2),161-4.

Lohmander, L.S., Ostenberg, A., Englund, M. \& Roos, H. (2004). High prevalence of knee osteoarthritis, pain, and functional limitations in female soccer players twelve years after anterior cruciate ligament injury. Arthritis \& Rheumatology, 50,3145-52. doi: 10.1002/art.20589. 
Umutlu, G., Erdoğan, A,T., ve Acar, N.,E.. (2019). Ön çapraz bağ ve medial menisküs yırtığının diz ekstansiyon ve fleksiyon izokinetik pik tork kuvvetine etkisi ve cybex test protokolü uygulaması: Vaka takdimi, CBÜ Beden Ĕgitimi ve Spor Bilimleri Dergisi, 14(1), 41-54.

Lund-Hanssen, H., Gannon, J., Engebretsen, L., Holen, K. \& Hammer, S. (1996). Isokinetic muscle performance in healthy female handball players and players with a unilateral anterior cruciate ligament reconstruction. Scandinavian Journal of Medicine \& Science in Sports, 6(3),172-5.

Noyes, F.R., Barber-Westin, S.D., Smith, S.T., Campbell, T. \& Garrison, T.J. (2012). A training program to improve neuromuscular and performance indices in female high school basketball players. The Journal of Strength \& Conditioning Research, 26(3),709-19.

Raunest, J., Sager, M. \& Bürgener, E. (1996). Proprioceptive mechanisms in the cruciate ligaments: An electromyographic study on reflex activity in the thigh muscles. The Journal of Trauma, 41(3),488-93.

Voskanian, N. (2013). Injury prevention in female athletes: review of the literature and practical considerations in implementing an ACL prevention program. Current Reviews in Musculoskeletal Medicine, 6(2), 158-163. 